line; as follows:-Some marked peculiarity is determined on to be made the subject of study. It may be an excess or deficiency of some normal character, or it may be a trait, a feature, a disease, or a monstrosity, the process being the same in all these cases. The inquirer then endeavours to trace its hereditary distribution. He fixes upon some individual who possesses the peculiarity in a highly marked degree, and traces the frequency and intensity with which it occurs among his kinsmen. He tries to do so exhaustively by compiling the facts relative to those kinsmen in each and every degree to as great a distance of kinship as he is able, or cares, to go. He follows a similar course in respect to many other individuals belonging to as many different families, and finally he obtains average results by well-known methods. I am speaking solely of inquiries

Distribution of the Peculiarity $\mathrm{X}$ in the Family of $\mathrm{A}$. $\mathrm{B}$.

$f a=$ Father or father's, according to its place ; similarly, me $=$ Mother $b r o=$ Brother ; $s i=$ Sister; so (or son where more euphonious)=Son The links in the chain of kinship are to be read as leading outwards from A.B. Thus, me da signifies "A.B.'s mother's daughter is." fa bro son means "A.B.'s father's brother's son is."

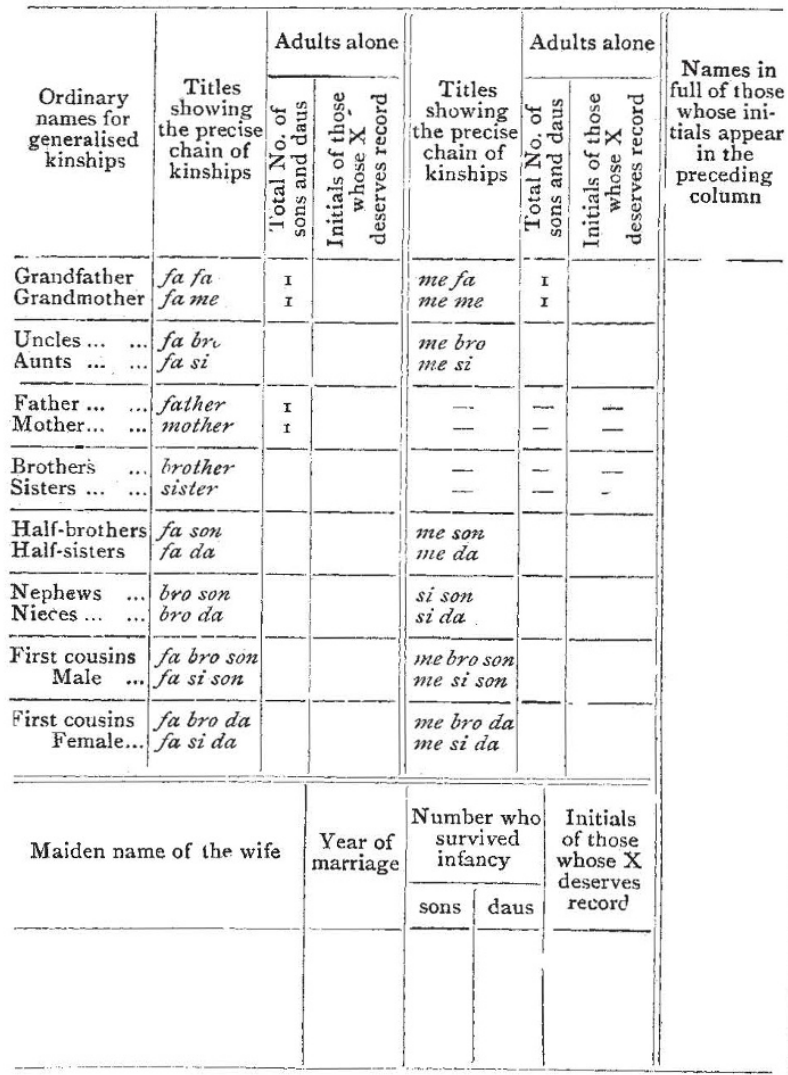

directed to what I would call the actuarial side of heredity, because they are analogous to those made by actuaries with medical experiences to determine the just rates of insurance in respect to expectation of life and other vital phenomena.

The ambiguity and cumbrousness of the ordinary terms of kinship are serious obstacles in carrying out these researches; it is also very difficult to present the results in a compact form by any established method. I have endeavoured to overcome both difficulties, the latter by the arrangement of the present table, and the former by the use of syllables, which give a perfectly distinctive description, and which, in addition to the advantage of brevity, have those of being easily intelligible, euphonious, even though they may be a trifle absurd, and capable of the most extended application. The details of the peculiarity $\mathrm{X}$, as they appear in the several persons named in the last column

No. 1787 , voI. 69] of the table, are supposed to be entered in a corresponding number of paragraphs on a separate sheet. After more trials and failures than would be easily credited, I think I have at last succeeded fairly well. Still, as I began by saying, I should be very grateful for useful suggestions. The table admits of indefinite extension, with no alteration of method. It will, of course, be understood that each successive step in the line of descent introduces a new element that may seriously affect the previous influences. Much might be added, but I think that with the aid of a little reflection the arrangement of the table will explain and justify itself.

FRANCIS GALTON.

\section{The Source of the Energy of Radium Compounds}

IF I understand Prof. Rutherford's communication aright (NATURE, January 7, p. 222), he concludes from the constancy of radio-active results with a solid radium salt and the same diluted that the energy of radium compounds cannot be derived from external sources. The matter is of such wide scientific interest that I ask your permission to present concisely the contra argument.

(I) When a coloured solid is dissolved the amount of absorption of light effected by the solid is equal to the amount of light absorbed by its solution. Thus I have shown that a plate of solid bichromate of potash 0.71 millimetre in thickness effects the same absorption of light as 6 centimetres of solution containing 0.0309 gram of the salt per cubic centimetre, as in each case the same number of bichromate molecules or molecular aggregates is acting on the light. To be perfectly clear, taking the specific gravity of bichromate of potash as 2.617 , we have in the former case a rectangular bundle of rays I square centimetre in section passing through $0.7 \mathrm{I} \times 0.2617=0.185^{8} \mathrm{gram}$ of solid, while the bundle of rays in the latter case passes through $6 \times 0.0309=0.1854$ gram of dissolved bichromate (see Chem. News, October 5, 1877).

(2) It has been amply demonstrated that the absorption of X-rays follows the same general laws as the absorption of light; thus the amount of both kinds of radiation absorbed increases ( $\mathrm{x}$ ) with the thickness of the body passed through, and (2) with the molecular weight in a comparable series of bodies ("The Old Light and the New," I896, pp. $73-80$ ).

Therefore if it be postulated that the energy of radium is due to the absorption of "an unknown external radiation" "similar in character to the radiations which are emitted," viz. the $\gamma$ rays, then the mere act of dilution of a milligram of radium bromide will not affect its constancy of absorption, and therefore also will not materially influence its radio-activity.

Borough Laboratory, Halifax, Yorks.

\section{$\gamma$-Rays from Radium.}

From the letter of Prof. Rutherford in Nature of January 7 it is improbable that $\gamma$ rays from radium are Röntgen rays generated by self-bombardment. The $\gamma$ rays must therefore arise from radium directly, and not as a secondary effect of bombardment.

It may be useful here to recall a remark made by Sir George Stokes at a meeting of the physical colloquium of the Owens College, Manchester, shortly before his death. Commenting on Becquerel rays, he likened the discharge of kathode rays to the discharge of a gun, the impact of kathode projectiles on a target creating an ethereal disturbance recognised as Röntgen rays. But, he said, in the same way as there is an explosive disturbance in the gun where the bullets issue, so there must also be a violent ethereal disturbance, not only where kathode rays strike, but also where they issue.

Is it not just this disturbance where $\beta$ rays issue which is now being detected in $\gamma$ rays, and is it not quite consistent with this view that the explosive disturbance of the atom which produces $z$ and $\beta$ rays should at the same. time generate something akin to Röntgen rays?

Io5 Freehold Street, Rochdale, January I6. 